\title{
Explanatory Variables as Evidence for Precision in Intramuscular Long-Acting Injections of Patients with Schizophrenia
}

\author{
Shigeaki Masuda1, Sakiko Sakamaki' ${ }^{2}$, Yuko Yasuhara ${ }^{3}$, Yueren Zhao ${ }^{4}$, Kensaku Takase5, \\ Yoshihiro Kai ${ }^{6}$, Tetsuya Tanioka ${ }^{3}{ }^{*}$, Rozzano C. Locsin ${ }^{3}$ \\ ${ }^{1}$ Department of Nursing, Nara Medical University, Nara, Japan \\ ${ }^{2}$ The Tokushima University Hospital, Tokushima, Japan \\ ${ }^{3}$ Department of Nursing Outcome Management, Institute of Biomedical Sciences, Tokushima University \\ Graduate School, Tokushima, Japan \\ ${ }^{4}$ Department of Psychiatry, Fujita Health University School of Medicine, Aichi, Japan \\ ${ }^{5}$ Department of Neurosurgery, Tokushima Central Prefectural Hospital, Tokushima, Japan \\ ${ }^{6}$ Department of Mechanical Engineering, Tokai University, Kanagawa, Japan \\ Email: masuda@naramed-u.ac.jp, “tanioka.tetsuya@tokushima-u.ac.jp
}

Received 8 December 2015; accepted 25 January 2016; published 28 January 2016

Copyright (C) 2016 by authors and Scientific Research Publishing Inc.

This work is licensed under the Creative Commons Attribution International License (CC BY). http://creativecommons.org/licenses/by/4.0/

c) (i) Open Access

\section{Abstract}

Intramuscular injections can cause damage to arteries, veins and nerves. Achieving maximum effects of medications through precise intramuscular (IM) injections must be assured and with certainty, particularly with long-acting injection drugs (LAI). The purpose of this study is to determine precision in IM LAIs of patients with schizophrenia. These evidences estimate "Distance from the Epidermis to the Under-Fascia" (DEUF) and "Distance from Epidermis to the Upper-Arm Bone" (DEB) of the deltoid muscle. Explanatory variables include body height, weight, body-mass index (BMI), deltoid-muscle circumference, fat percentage and muscle mass measured by body composition monitor. Sixty nine subjects are included based on the Diagnostic Statistical Manual of Mental Disorders (DSM-IV, 1994), and receive treatments of typical and atypical antipsychotic LAI. There are 46 males and 23 females with average age of 51.41 (Standard Deviation $=13.58$ ) and ranging from 21 to 81 years who are all right-handed. Ultrasonographic data and those from explanatory variables are calculated using Spearman's rank correlation coefficients. Multiple regression analysis (step-wise method/forced input method) is performed assuming DEUF or DEB as dependent variables. Significant correlations are found with highest adjusted R-square. Paired t-tests show differences in average values of actual ultrasonographic measurements assigned to DEUF or DEB, and the regression equations for accuracy. Ultrasonographic values are assigned multiple-regres-

\footnotetext{
${ }^{*}$ Corresponding author.
} 
sion equations as true values, and the calculated values are compared with those obtained by regression equations. There are no significant differences observed for either the right or left arm. The multiple regression equations for BMI and fat percentages (upper extremity estimation) of DEUF, and for BMI and injection site circumference of estimated DEB, successfully value the DEUF and DEB. By using these multiple regression equations for IM injection to the deltoid-muscle, DEUF can better ensure accurate LAI into the muscle through body monitor, DEB, and measured values of the deltoid-muscle injection site circumference.

\section{Keywords}

Estimating Equation, Long Acting Injectable, Deltoid Muscle, Schizophrenia

\section{Introduction}

As the muscular layers are under the subcutaneous tissue, muscle injections carry a high risk of damages to the arteries, veins and nerves as compared with intradermal injection and subcutaneous injection [1]. For example, in Japan in the 1970s, cases of quadriceps femoris muscle contractures of children were realized as a social issue [2]. Historically, the following situations are recognized: 1) muscle injections of antipyretic agents, antibiotic agents or a mixture of both for the cold syndrome are conducted for children at the demand of parents, in particular, without careful consideration, cases of muscle contracture often occur; 2) at that time, subcutaneous injections of large amount of glucose and ringer's solutions are given to children; 3) the cases of not only the contractures of quadriceps muscle but also those of the deltoid muscles and gluteal muscles are also found not only in children, but in adults. Therefore, intramuscular (IM) injections become less frequent and popular.

In Japan, common vaccinations are performed through subcutaneous injection, but are done intramuscularly in other countries [3]. The Japan Pediatric Society is appealing for the appropriate dose of vaccine which can be given by IM injection because of the high immunogenicity of a part of the vaccines, that can lead to less adverse events such as red flare and aching pain related to vaccination [3] [4]. There are some discussions to consider IM injection as appropriate route for vaccinations.

Most cases of schizophrenia are chronic conditions in which a continuous life-long drug dosing is often required for the prevention of recurrence. If the symptoms can be controlled by drug therapy, the patients can live their daily lives in their own community. Therefore, their quality of life is dependent on whether or not they can continue their drug therapy. However, for the treatment of patients with schizophrenia, because of their poor understanding of their own disease, continuing drug therapy is said to be difficult. Therefore, an atypical antipsychotic long-acting injection (LAI) into the muscle from which a sustainable and stable therapeutic effect can be expected for a certain period is a priority [5].

LAI is designed to be dissolved and to decompose at the muscle injection site and disseminated into the general circulation for several weeks [6]. In order to achieve the maximum effect of the drug, it is important to precisely inject LAI into the muscle. If the medical solution is injected subcutaneously, induration, red flare and/or abscess may possibly occur [5]. When such an adverse event is observed, it limits the selection of injection sites to avoid the site where the adverse event occurs, and lowers the patients' adherence to the therapy because of aching pain, increasing the possibility of exacerbating the symptoms of schizophrenia. As a result, it will cause negative effects on patient recuperation because of the adverse effect caused by alteration in the therapeutic regimen [7].

The deltoid muscle and gluteal medius muscle are often selected for muscle injection in psychiatric cases as with other conditions [8]. The muscle mass of the deltoid muscle is smaller than that of the gluteal medius muscle, and its muscular layer is also thinner. There are cases in Japan where the axillary nerve deltoid branch and blood vessels run along the deltoid region [9]-[11], therefore, it is important to understand that this is a dangerous area to use for IM injections. The injection site in the deltoid muscle is variously cited as "slightly anterior from three fingers' breadth below the acromion process", "anterior-half part of the deltoid muscle from about three fingers' breadth below acromion" [12]-[14] and "from 'distal $4 \mathrm{~cm}$ to acromion' to 'behind the center of acromion process in the central side”" [15]. This shows that three selection methods for safe injection sites have 
not been standardized.

As the three fingers' breadth below the acromion is affected by the thickness of the fingers of those who perform the injection, the deltoid muscle injection site becomes different according to the practitioners' fingers. The site of "three fingers' breadth below the acromion" is possibly affected by the individual differences of muscle and finger breadths of both the practitioners and the patients' gender, physical constitution, BMI (Body mass index), etc. [16].

Among the research conducted on the needle insertion depth in the deltoid muscle, there is research that uses ultrasonography targeting health people. Kikuchi et al. [17] developed a formula to assess the subcutaneous tissue thickness from the BMI which was in association with the BMI that was identified. Takahashi et al. [18] reported that in the case of IM injection into the site $5 \mathrm{~cm}$ below the acromion of the deltoid muscle, if the needle insertion depth is $15 \mathrm{~mm}$ for those with BMI from 18.5 to $30 \mathrm{~kg} / \mathrm{m}^{2}$ and $20 \mathrm{~mm}$ for those with BMI of more than $30.0 \mathrm{~kg} / \mathrm{m}^{2}$, the needle reaches the under-fascia and is in the position where it does not touch the upper-arm bone in both males and females. As the method of objectively assessing the distance from the epidermis of the deltoid muscle to the muscle layer or upper-arm bone, there are measuring methods such as using ultrasonography, BMI, and adipometers (fat measuring calipers) [19]. However, there is the possibility of errors occurring caused by measurements in using calipers, such as the measurement site and the person doing the measurement [20].

All the preceding research studies targeted healthy people. No research studies targeting actual patients with schizophrenia have been conducted. However, there is a report that the prevalence of obesity is high among patients with mental illness [19]. In order to make it possible to safely inject medications into the muscles targeting patients with schizophrenia and anticipate a stable drug effect, it is vitally important to establish a precise "method to estimate the range from which medications can be injected into the muscle without the injection needle reaching the upper-arm bone" which may cause adverse effects.

The purpose of this research was to determine the possibility of estimating the "Distance from the Epidermis to the Under-Fascia (DEUF)" and "Distance from Epidermis to the Upper-Arm Bone (DEB)" of the deltoid muscle injection site for patients with schizophrenia, using the explanatory variables of body height, body weight, BMI, deltoid-muscle injection site circumference and fat percentage, and muscle mass measured by a body composition monitor.

\section{Materials and Methods}

\subsection{Subject}

The subjects met the diagnostic standard of schizophrenia of the Diagnostic and Statistical Manual of Mental Disorders, Fourth Edition (DSV-IV: the American Psychiatric Association, 1994). The inclusion criteria were patients had an injections of a LAI therapy who were $\geq 18$ years of age. Exclusion criteria included an active alcohol or substance abuse, or current pregnancy/lactation. They were patients with schizophrenia receiving treatment of typical and atypical antipsychotic long-acting injection (LAI) in the two hospitals in Kumamoto Prefecture and Aichi Prefecture, Japan. The number of hospital beds and the average length of a hospital stay are following: hospital in Kumamoto Prefecture (234 beds and 231 days), and hospital in Aichi Prefecture (315 beds and 132 days). The number of subjects were 69 (46 males and 23 females) with an average age of 51.41 (Standard deviation $=13.58$ ), and ranging from 21 to 81 years. Amount muscles may differ depending on the difference in the dominant hand, all subjects were right-handed. The subjects agreed to participate in the research.

\subsection{Study Period}

A prospective cross-sectional study was conducted, and period was from June 2012 to October 2013.

\subsection{Measures and Statistical Methods}

\subsubsection{Measurement by Ultrasonography}

An ultrasonography machine of HI VISION AVIUS (Hitachi-Aloka Medical Co. Mitaka City) and a linear probe with a frequency of $735 \mathrm{MHz}$ were used. The measurement was conducted by an expert clinical laboratory technologist. The site at three fingers' breadth below the acromion, which is considered to be an appropriate deltoid muscle injection site at present [14], was selected as the injection site, and the subject's own three fin- 
gers' breadth was used. For the left arm, the breadth of three fingers from the second finger to fourth finger of the right hand was used, and for the right arm, that of the left hand was used. The measurement site was marked with water-based ink identifying the DEUF and DEB (mm) of the sites.

\subsubsection{Measurement of Deltoid Muscle Injection Site Circumference}

The circumference of the injection site was marked using a ruler.

\subsubsection{Measurement Using a Body Monitor}

Body height (cm), body weight ( $\mathrm{kg})$, BMI $\left(\mathrm{kg} / \mathrm{m}^{2}\right)$, fat percentages (\%) of the whole body, body trunk, left upper extremity and right upper extremity (hereafter referred to as "fat percentage"), and the muscle masses (kg) of the whole body, body trunk, left upper extremity and right upper extremity (hereafter referred to as "muscle mass") were measured using a body monitor (InnerScan ${ }^{\circledR 50 V-T A N I T A) . ~}$

\subsubsection{Analysis Method}

Spearman's rank correlation coefficients of the DEUF and DEB measurement data by ultrasonography and the items of body height, body weight, BMI, muscle mass, fat percentage and deltoid-muscle injection site circum ference were calculated. Multiple regression analysis (stepwise method/forced input method) was performed assuming DEUF or DEB as the dependent variable, and the aforementioned items in which significant correlation were recognized as explanatory variables. The results indicated an adjusted $\mathrm{R}^{2}$ as highest was employed. A paired $t$-test was conducted to test the difference in average values of the actual ultrasonographic measured values assigned to DEUF or DEB and the regression equation for the purpose of establishing accuracy of data. The ultrasonographic measured values and predicted value by regression equation was calculated by Pearson product-moment correlation coefficient. Power analysis for a multiple regression with two predictors was conducted in $G^{*}$ Power to determine a sufficient sample size using an alpha of 0.05 , a power of 0.80 , and a medium effect size ( $(\mathrm{f} 2=0.15)$. Based on the aforementioned assumptions, the desired sample size was 55 .

\subsection{Ethical Consideration}

This research was conducted with the approval (approval number 2948) of the Ethical Committee of the Tokushima University Hospital. The cooperative hospitals were asked to have their primary doctors select candidates for this research among their patients with schizophrenia under LAI treatment. Then, the collaborators explained the purpose, contents and method of this research study verbally and in writing to the prospective subjects. Those who consented to participate were regarded as subjects. The following were described in the consent letter: 1) the subjects' agreement to participate out of their own free will; 2) if they agree to participate in this research, they can discontinue it at any time; and 3) no disadvantage will be caused by cancellation of participation and cooperation.

\section{Results}

Table 1 shows the basic physical information and the results of the measurement of deltoid muscle injection site circumference, DEUF and DEB.

\subsection{Relationship between DEUF and DEB, and Variables}

\subsubsection{Relationships between DEUF and Variables}

The correlations between the right and left DEUFs and the variables of body height, body weight, BMI, fat percentage, muscle mass and deltoid muscle injection site circumference are shown in Table 2. Significant positive correlations were recognized between DEUF and the variables of body weight, BMI, fat percentage (whole body, body trunk, left upper extremity and right upper extremity) and deltoid muscle injection site circumference. However, no significant correlation with body weight and muscle mass was recognized except of the left arm's DEUF and whole-body muscle mass.

\subsubsection{Relationship between DEB and Variables}

The correlations between the right and left DEBs and the variables of body height, bodyweight, BMI, fat per- 
Table 1. Characteristics of physical information.

\begin{tabular}{|c|c|c|c|c|c|c|}
\hline Item & & & Mean & $\begin{array}{l}\text { Standard } \\
\text { Deviation }\end{array}$ & Minimum & Maximum \\
\hline \multirow{6}{*}{ Basic Information } & \multicolumn{2}{|r|}{ Age } & 51.41 & 13.58 & 21.00 & 81.00 \\
\hline & \multicolumn{2}{|c|}{ Height $(\mathrm{cm})$} & 164.20 & 7.89 & 146.10 & 179.00 \\
\hline & \multicolumn{2}{|c|}{ Weight (kg) } & 69.72 & 14.80 & 39.20 & 105.60 \\
\hline & \multicolumn{2}{|c|}{$\operatorname{BMI}\left(\mathrm{kg} / \mathrm{m}^{2}\right)$} & 25.72 & 4.73 & 17.27 & 39.70 \\
\hline & \multirow{2}{*}{ DMISC (cm) } & Left & 34.51 & 4.59 & 23.40 & 47.20 \\
\hline & & Right & 34.65 & 4.93 & 23.90 & 47.20 \\
\hline \multirow{4}{*}{$\begin{array}{l}\text { Measurement by } \\
\text { ultrasonography }\end{array}$} & \multirow{2}{*}{ DEUF (mm) } & Left & 7.67 & 2.47 & 3.50 & 17.20 \\
\hline & & Right & 7.73 & 2.35 & 3.80 & 18.50 \\
\hline & \multirow{2}{*}{$\mathrm{DEB}(\mathrm{mm})$} & Left & 27.69 & 6.79 & 12.20 & 44.80 \\
\hline & & Right & 26.12 & 6.35 & 12.70 & 47.50 \\
\hline \multirow{8}{*}{$\begin{array}{l}\text { Measurement using a } \\
\text { body monitor }\end{array}$} & \multirow{4}{*}{$\begin{array}{c}\text { Fat percentage } \\
(\%)\end{array}$} & Whole body & 33.70 & 13.54 & 8.30 & 62.90 \\
\hline & & Body trunk & 30.05 & 10.41 & 14.00 & 61.90 \\
\hline & & Left upper extremity & 21.93 & 10.00 & 1.90 & 49.10 \\
\hline & & Right upper extremity & 23.22 & 9.23 & 7.10 & 18.30 \\
\hline & \multirow{4}{*}{$\begin{array}{c}\text { Muscle mass } \\
(\mathrm{kg})\end{array}$} & Whole body & 41.97 & 12.30 & 15.90 & 69.55 \\
\hline & & Body trunk & 26.03 & 9.02 & 10.60 & 51.80 \\
\hline & & Left upper extremity & 2.30 & 0.55 & 1.20 & 3.40 \\
\hline & & Right upper extremity & 2.15 & 0.58 & 1.05 & 3.50 \\
\hline
\end{tabular}

BMI: Body Mass Index; DMISC: Deltoid Muscle Injection Site Circumference; DEUF: Distance from the Epidermis to the Under-Fascia; DEB: Distance from the Epidermis to the Upper-Arm Bone; $N=69,46$ (67\%) of the patients were males, and 23 (33\%) were female.

Table 2. The correlations between the right and left DEUFs/DEBs/ and the variables of body height, bodyweight, BMI, fat percentage, muscle mass and deltoid muscle injection site circumference.

\begin{tabular}{|c|c|c|c|c|c|}
\hline & & \multicolumn{4}{|c|}{ Ultrasonography } \\
\hline & & \multicolumn{2}{|c|}{ DEUF } & \multicolumn{2}{|c|}{ DEB } \\
\hline & & Left & Right & Left & Right \\
\hline \multicolumn{2}{|c|}{ Height (cm) } & -0.064 n.s. & -0.194 n.s. & 0.094 n.s. & 0.201 n.s. \\
\hline \multicolumn{2}{|c|}{ Weight (kg) } & $0.520^{* *}$ & $0.508^{* *}$ & $0.636^{* *}$ & $0.748^{* *}$ \\
\hline \multicolumn{2}{|c|}{ BMI $\left(\mathrm{kg} / \mathrm{m}^{2}\right)$} & $0.630^{* *}$ & $0.667^{* *}$ & $0.691^{* *}$ & $0.751^{* *}$ \\
\hline \multirow{2}{*}{ DMISC $(\mathrm{cm})$} & Left & $0.459^{* *}$ & - & $0.577^{* *}$ & - \\
\hline & Right & - & $0.496^{* *}$ & - & $0.679^{* *}$ \\
\hline \multicolumn{6}{|c|}{ Body monitor } \\
\hline \multirow{4}{*}{$\begin{array}{c}\text { Fat } \\
\text { percentage } \\
(\%)\end{array}$} & Whole body & $0.263^{*}$ & $0.378^{* *}$ & $0.290^{*}$ & $0.327^{* *}$ \\
\hline & Body trunk & $0.581^{* *}$ & $0.426^{* *}$ & $0.288^{*}$ & $0.296^{*}$ \\
\hline & Left upper extremity & $0.505^{* *}$ & - & $0.275^{*}$ & - \\
\hline & Right upper extremity & - & $0.591^{* *}$ & - & 0.168 n.s. \\
\hline \multirow{4}{*}{$\begin{array}{l}\text { Muscle mass } \\
\quad(\mathrm{kg})\end{array}$} & Whole body & $0.250^{*}$ & 0.142 n.s. & 0.213 n.s. & $0.259^{*}$ \\
\hline & Body trunk & 0.061 n.s. & 0.230 n.s. & $0.286^{*}$ & $0.328^{* *}$ \\
\hline & Left upper extremity & 0.098 n.s. & - & $0.456^{* *}$ & - \\
\hline & Right upper extremity & - & -0.042 n.s. & - & $0.398^{* *}$ \\
\hline
\end{tabular}

BMI: Body Mass Index; DMISC: Deltoid Muscle Injection Site Circumference; DEUF: Distance from the Epidermis to the Under-Fascia; DEB: Distance from the Epidermis to the Upper-Arm Bone; Spearman Rank correlation coefficient: ${ }^{*} p<0.05,{ }^{* * *} p<0.001$; n.s.: Not significant. 
centage, muscle mass and deltoid muscle injection site circumference are shown in Table 2. Significant positive correlations were recognized between the right and left DEBs and the variables of body weight, BMI, deltoid muscle injection site circumference, fat percentage (whole body, body trunk and left upper extremity) and muscle mass (upper extremity and body trunk). However, no significant correlations were recognized between the right and left DEBs and body height, or between the left DEB and the whole-body muscle.

\subsection{Discussion of Multiple Regression: DEUF and DEB as Dependent Variables}

\subsubsection{Discussion of Multiple Regression Equation to Estimate DEUF}

Relationship between DEUF and both BMI and fat percentage of the upper extremity

The analytical results of the relationships between the left and right DEUFs, and BMI and body fat percentage of the upper extremity are shown in Table 3 . The adjusted $\mathrm{R}^{2}$ for the left arm was 0.503 , and that for the right arm was 0.577 .

As a result, as the adjusted $\mathrm{R}^{2}$ of both arms were the highest as a multiple regression equation for calculating DEUF, it was employed as a prediction expression.

$$
\begin{gathered}
\text { Left DEUF y }=-1.481+0.318 \times \mathrm{BMI}+0.044 \times \text { fat percentage }(\text { left arm) }(1) \\
\text { Right DEUF y }=-1.302+0.278 \times \mathrm{BMI}+0.081 \times \text { fat percentage }(\text { right arm) }(2)
\end{gathered}
$$

\subsubsection{Discussion of Multiple Regression Equation for DEB}

Relationships between DEB and both deltoid-muscle injection site circumference and BMI

The analytical results of the relationships between the left and right DEBs, and deltoid-muscle injection site circumference and BMI are shown in Table 4. The adjusted $\mathrm{R}^{2}$ for the left arm was 0.489 , and that for the right arm was 0.577 .

As the adjusted $\mathrm{R}^{2}$ of both arms were the highest as a multiple regression equation for calculating DEB, it was employed as a prediction equation.

\begin{tabular}{|c|c|c|c|c|c|c|c|c|}
\hline & & \multicolumn{7}{|c|}{ 95\% confidence interval } \\
\hline & & PRC (B) & $\operatorname{SPRC}(\beta)$ & $\mathrm{R}^{2}$ & Adjusted $\mathrm{R}^{2}$ & Minimum & Maximum & Probability \\
\hline & Constant terms & -1.481 & & 0.518 & 0.503 & -3.837 & 0.875 & n.s. \\
\hline Left & BMI & 0.318 & 0.608 & & & 0.213 & 0.094 & $* *$ \\
\hline DEUF & $\begin{array}{l}\text { Fat percentage } \\
\text { (left arm) }\end{array}$ & 0.044 & 0.180 & & & -0.005 & 0.423 & n.s. \\
\hline & Constant terms & -1.302 & & 0.589 & 0.577 & -3.349 & 0.746 & n.s. \\
\hline Right & BMI & 0.278 & 0.560 & & & 0.189 & 0.368 & ${ }^{* *}$ \\
\hline DEUF & $\begin{array}{l}\text { Fat percentage } \\
\text { (right arm) }\end{array}$ & 0.081 & 0.318 & & & 0.035 & 0.126 & * \\
\hline
\end{tabular}

\section{Table 3. Relationship between DEUF and both BMI and fat percentage of the upper extremity.}

PRC: Partial regression coefficient; SPRC: Standard partial regression coefficient; DEUF: Distance from the Epidermis to the Under-Fascia; BMI: Body Mass Index; n.s.: Not significant, ${ }^{*} p<0.05,{ }^{* *} p<0.001$.

\begin{tabular}{|c|c|c|c|c|c|c|c|c|}
\hline & & \multirow[b]{2}{*}{ PRC (B) } & \multirow[b]{2}{*}{$\operatorname{SPRC}(\beta)$} & \multirow[b]{2}{*}{$\mathrm{R}^{2}$} & \multicolumn{4}{|c|}{ 95\% Confidence interval } \\
\hline & & & & & Adjusted $\mathrm{R}^{2}$ & Minimum & Maximum & Probability \\
\hline \multirow{3}{*}{$\begin{array}{l}\text { Left } \\
\text { DEB }\end{array}$} & Constant terms & -0.391 & & & & -9.637 & 8.855 & n.s. \\
\hline & BMI & 0.998 & 0.696 & 0.504 & 0.489 & 0.503 & 1.493 & $* *$ \\
\hline & L-DMISC & 0.024 & 0.016 & & & -0.485 & 0.534 & n.s. \\
\hline \multirow{3}{*}{$\begin{array}{l}\text { Right } \\
\text { DEB }\end{array}$} & Constant terms & -1.888 & & & & -9.163 & 5.388 & n.s. \\
\hline & BMI & 0.746 & 0.555 & 0.589 & 0.577 & 0.304 & 1.187 & ${ }^{*}$ \\
\hline & R-DMISC & 0.300 & 0.233 & & & -0.124 & 0.724 & n.s. \\
\hline
\end{tabular}

Table 4. Relationships between DEB and both deltoid-muscle injection site circumference and BMI.

PRC: Partial regression coefficient; SPRC: Standard partial regression coefficient; L-DMISC: Left deltoid-muscle injection site circumference; R-DMISC: Right deltoid-muscle injection site circumference; DEB: Distance from the Epidermis to the Upper-Arm Bone; BMI: Body Mas Index; n.s.: Not significant, ${ }^{*} p<0.05,{ }^{* *} p<0.001$. 
Left DEB y $=-0.391+0.998 \times$ BMI $+0.024 \times$ left deltoid-muscle injection site circumference (1)

Right DEB y $=-1.888+0.746 \times \mathrm{BMI}+0.3 \times$ right deltoid-muscle injection site circumference (2)

\subsection{Confirmation of the Accuracy of the Developed Regression Equation}

\subsubsection{Discussion of the Accuracy of Regression Equation of DEUF}

As shown in Table 5, in order to confirm the accuracy of the multiple regression equation, DEUFs measured by ultrasonography were assigned as true values to the multiple regression equation and the calculated values were compared with the values calculated by regression equation. The result showed no significant differences observed in either the right $(t=-0.027, p=0.978)$, or left arm $(t=-0.005, p=0.996)$.

\subsubsection{Discussion of Accuracy of Regression Equation of DEB}

As shown in Table 6, in order to confirm the accuracy of the multiple regression equation, the ultrasonographic measured values were assigned to the multiple-regression equation as true values, and the calculated values were compared with the values calculated by regression equation. As a result, no significant differences were observed in either the right $(t=-0.026, p=0.980)$ or left arm $(t=0.000, p=1.000)$.

The relationship between the values assigned to the DEB multiple regression equation and the values measured by ultrasonography, and the relationship between the values assigned to the DEUF multiple-regression equation and the values measured by ultrasonography are shown in Figure 1-Left arm and Figure 2-Right arm. The horizontal axis shows the BMI variable for both DEUF and DEB.

Table 5. Compared result of DEUF: calculated values by regression equation VS measured values by ultrasonography.

\begin{tabular}{|c|c|c|c|c|c|c|c|c|c|c|c|}
\hline \multirow{4}{*}{$\begin{array}{l}\text { Deltoid } \\
\text { muscle }\end{array}$} & & \multicolumn{4}{|c|}{ Calculated values by regression equation } & \multicolumn{4}{|c|}{ Measured values by ultrasonography } & \multirow{3}{*}{$\begin{array}{l}\text { t-value } \\
-0.027\end{array}$} & \multirow{3}{*}{$\begin{array}{c}\text { P-value } \\
0.978\end{array}$} \\
\hline & & \multirow{2}{*}{$\begin{array}{l}\text { Mean } \\
7.663\end{array}$} & \multirow{2}{*}{$\begin{array}{c}\text { SD } \\
1.777\end{array}$} & \multicolumn{2}{|c|}{ Range } & \multirow{2}{*}{$\begin{array}{l}\text { Mean } \\
7.668\end{array}$} & \multirow{2}{*}{$\begin{array}{c}\mathrm{SD} \\
2.472\end{array}$} & \multicolumn{2}{|c|}{ Range } & & \\
\hline & Left & & & 4.620 & 13.050 & & & 3.500 & 17.200 & & \\
\hline & Right & 7.728 & 1.806 & 4.440 & 13.230 & 7.729 & 2.351 & 3.800 & 18.500 & -0.005 & 0.996 \\
\hline
\end{tabular}

Paired t-test; SD: Standard Deviation; DEUF: Distance from the Epidermis to the Under-Fascia.

Table 6. Compared result of DEB: calculated values by regression equation VS measured values by ultrasonography.

\begin{tabular}{ccccccccccccc}
\hline & & \multicolumn{3}{c}{ Calculated values by regression equation } & \multicolumn{3}{c}{ Measured values by ultrasonography } \\
& & Mean & SD & \multicolumn{2}{c}{ Range } & Mean & SD & \multicolumn{2}{c}{ Range } & t-value & P-value \\
\hline $\begin{array}{c}\text { Deltoid } \\
\text { muscle }\end{array}$ & Left & 26.104 & 4.817 & 17.500 & 40.360 & 26.119 & 6.789 & 12.200 & 44.800 & -0.026 & 0.980 \\
DEB & Right & 27.693 & 4.877 & 18.170 & 41.890 & 27.693 & 6.354 & 12.700 & 47.500 & 0.000 & 1.000 \\
\hline
\end{tabular}

Paired t-test; SD: Standard Deviation; DEB: Distance from the Epidermis to the Upper-Arm Bone.
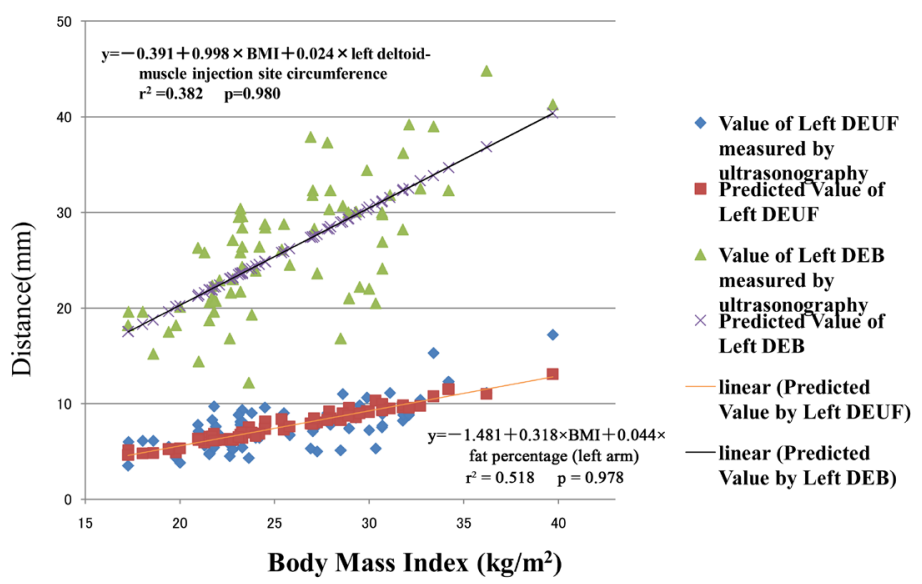

Figure 1. Relationship between the values assigned to the DEUF/DEB multiple regression equation and the values measured by ultrasonography (Left-arm) 


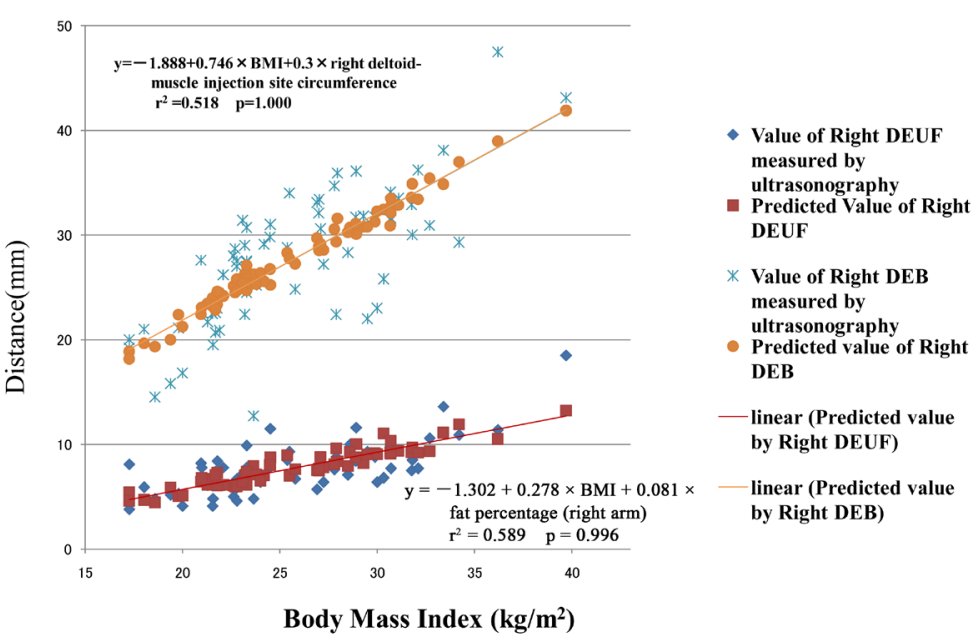

Figure 2. Relationship between the values assigned to the DEUF/DEB multiple regression equation and the values measured by ultrasonography (Right-arm).

\section{Discussion}

The correlation with DEUF of which is recognized, is a BMI showing the degree of obesity obtained from body weight and body height [18]. This was considered to be useful as explanatory variables. Also, the fat percentage of the arm, which is considered to be useful as rough indication of subcutaneous fat thickness of upper arm, was recognized to have significantly high correlations with the DEUF, and fat percentage was considered to be useful as an explanatory variable for obtaining a regression equation. Deltoid muscle injection site circumference is the circumference of a circle having a diameter covering the upper-arm bone, subcutaneous fat thickness and muscle layer. It is a measured value closely related to the fat layer and muscle layer. Its significantly high correlation with the fat layer and muscle layer is recognized and it was considered to be useful as an explanatory variable for obtaining a regression equation.

From the result of a comparison of adjusted $\mathrm{R}^{2}$, DEUF and the value calculated by the multiple regression equation, the prediction equation with explanatory variables of BMI and fat percentage (upper extremity) was considered to be able to accurately estimate DEUF at the deltoid muscle injection site. In this research, there were cases where DEUF epidermis, measured by ultrasonography, was longer than that estimated by multiple regression equation. There were six cases where the needle was estimated to reach only up to more than $2 \mathrm{~mm}$ before the target in subjects' right arms, eight for the left arm, and the maximum error was $5.2 \mathrm{~mm}$. Three subjects among the six were among the four whose DEUF was determined to be thick by ultrasonic measurement. When a prediction equation is used, if the thickness of subcutaneous tissue is more than $10 \mathrm{~mm}$, it is possible that the needle does not reach the muscle layer.

In order to discuss a multiple regression equation of DEB, a multiple regression analysis was performed by forced input method regarding deltoid muscle injection site circumference and BMI as explanatory variables. It is considered that by using a combination of the deltoid muscle injection site circumference and BMI measured by a ruler, multi regression Equation (1) acquired the prediction accuracy of $\mathrm{R}^{2}$ of 0.489 and multi regression Equation (2) acquired that of $\mathrm{R}^{2}$ of 0.577 . In order to further confirm the accuracy of the multiple-regression equations obtained, the DEB of the deltoid-muscle injection site as a true value was compared with the actual measured value assigned to the regression equation, and as a result, no statistic difference was observed.

The maximum error was approximately $13.6 \mathrm{~mm}$ on the right side, and $12.2 \mathrm{~mm}$ on the left side. As being discussed in preceding research [18], BMI was an explanatory variable useful for the prediction equation from the epidermis to the upper-arm bone. However, as shown in Figure 1 and Figure 2, in this prediction equation, when the value of BMI becomes larger, predicted DEB is sometimes calculated longer than DEB measured by ultrasonography. For the deltoid-muscle injection site circumference, another variable, it is difficult to precisely measure the circumference around the upper arm, because it is sometimes fastened by tape measure, the measured value by tape measure often fluctuates. Therefore, some errors were observed in the measurement of the upper arm. In the right side of the predicted DEB value, 6 people were short (range: 0.50-8.55), 6 people were 
almost no difference (less than $0.5 \mathrm{~mm}$ ), and 27 people were long (range: $0.51-13.55$ ) compared to the value measured by ultrasonography. In the left side, 32 people were short (range: $0.70-10.50$ ), 8 people were almost no differences (less than $0.5 \mathrm{~mm}$ ), and 29 people were long (range: 0.68-12.16). Therefore, in case of the predicted value was longer than the actual value, it was considered the injection needle might actually to contact with the upper-arm bone.

Takahashi et al. [18] recommend that in the case of $5 \mathrm{~cm}$ below the acromion of the deltoid muscle, if $18.5 \leq$ $\mathrm{BMI}<30.0$, injection insertion length is $1.5 \mathrm{~cm}$, if $\mathrm{BMI} \geq 30.3$, injection insertion length is $2.0 \mathrm{~cm}$ and encourage to discuss the other site if BMI $<18.5$. However, there may be differences in injection-needle penetration depth by individuals. In clinical practice, in order to make sure that the point of a needle reaches within the muscle and does not harm the upper-arm bone, a method to confirm if the predicted value is not in the range to touch the upper-arm bone is indispensable. Specifically, in order to precisely be injected into the muscle, the assessment of skin-fold thickness is important. Pinch up the skin of the injection site, regard about half of the thickness as the subcutaneous tissue, and add about $4 \mathrm{~mm}$ to the thickness. It is considered to be useful to take this method into consideration [16] [21]. Depending on circumstances, it may be necessary to recommend the injection into the gluteal medius muscle not only to thin people with BMI $<18.5$ whose deltoid-muscle mass is small, but also anyone who has experienced an adverse event even once.

The prediction equation obtained in this research is considered to be useful as a method to assess the injection sites from which the injection needle can certainly reach the muscle layer and does not harm the upper-arm bone. However, when using the estimation equation DEB, it is important to take the value of BMI and the thickness of the subcutaneous tissue into consideration.

\section{Limitation}

Although the research result of Takahashi et al. [18] is very useful in that the injection-needle penetration depth can be easily selected, it is different from this research in that it targeted healthy people, and all deltoid-muscle injection sites were unified to $5 \mathrm{~cm}$ below acromion. It is also required to examine the influence caused by the difference in BMI to multiple-regression equation in our research.

This research targeted the patients with schizophrenia under LAI treatment. The subjects of this research were all right-handed. It is considered that depending upon whether right-handed or not, the frequency of use of muscle when carrying things and how to exert strength become different, and it makes a difference in muscle mass; therefore, it is necessary to increase the number of subjects to examine how whether right-handed or not exerts influence DEUF and DEB. In order to confirm the accuracy of the multiple regression equation obtained in this research, it is required to collect the data of the presence and degree of error between the predicted values and those measured by ultrasonography and other measurements. Furthermore, it is also required to proceed with the discussion of safety of the method for determining an injection site using the patients' own three fingers' breadth.

As challenges for the future, it is necessary to enhance the accuracy of the estimate equation, multivariate analyses that include the disease duration of schizophrenia and level of disease of these patients.

\section{Conclusions}

The research confirmed that correlations between DEUF and DEB were measured by ultrasonography, and the fat percentage and muscle mass were measured by body monitor, and the injection site circumference was measured by a ruler for the first time survey report.

The multiple regression equation obtained regarding BMI and fat percentage (upper extremity) as explanatory variables for the estimation of DEUF, and the multiple regression equation obtained regarding BMI and injection site circumference as explanatory variables for the estimation of DEB, could estimate DEUF and DEB, respectively.

By using these multiple regression equations, for muscle injection to the deltoid-muscle injection site, DEUF could better ensure medical liquid injection into the muscle, owing to the values measured by body monitor, and $\mathrm{DEB}$, owing to the measured value of the deltoid-muscle injection site circumference.

\section{Acknowledgements}

The authors would like to thank subject patients and all staff members of the hospital who have helped this re- 
search.

\section{References}

[1] Takada, S. and Kawanishi, C. (2006) Injection Skills Based upon Evidence. Nakayama Shoten Co. Ltd., Tokyo, 123-128. (In Japanese)

[2] Japan Pediatric Society (1983) Muscle Contracture Committee. Report Concerning Muscle Contracture, 87, 10671055. (In Japanese)

[3] Japan Pediatric Society (2011) Change of Description on the Attached Document for Muscle Injection of Inactivated Vaccine. (In Japanese) http://www.jpeds.or.jp/uploads/files/saisin_1106273.pdf

[4] Petousis, H.H. (2008) Vaccine Injection Technique and Reactogenicity_Evidence for Practice. Vaccine, 26, 62996304. http://dx.doi.org/10.1016/j.vaccine.2008.08.052

[5] Hamann, G.L., Egan, T.M., Wells, B.G. and Grimmig, J.E. (1990) Injection Site Reactions after Intramuscular Administration of Haloperidol Decanoate $100 \mathrm{mg} / \mathrm{mL}$. Journal of Clinical Psychiatry, 51, 502-504.

[6] Remington, G., Mamo, D., Labelle, A., Reiss, J., Shammi, C., Mannaert, E., Mann, S. and Kapur, S. (2006) A PET Study Evaluating Dopamine $\mathrm{D}_{2}$ Receptor Occupancy for Long-Acting Injectable Risperidone. The American journal of psychiatry, 163(3), 396-401. http://dx.doi.org/10.1176/appi.ajp.163.3.396

[7] Dibonaventura, M., Gabriel, S., Dupclay, L., Gupta, S. and Kim, E. (2012) A Patient Perspective of the Impact of Medication Side Effects on Adherence: Results of a Cross-Sectional Nationwide Survey of Patients with Schizophrenia. BMC Psychiatry, 12, 20. http://dx.doi.org/10.1186/1471-244X-12-20

[8] Takahashi, Y., Kikuchi, K., Oyama, N., Ishida, Y. and Sato, F. (2007) Investigation about the Intramuscular Injection Method Prevent Medication from Leaking back onto the Skin in Psychiatry. Journal of the Faculty of Nursing (Iwate Prefectural University), 9, 103-112. (In Japanese)

[9] Iwanaga, H. and Takayama, S. (2003) A Study of the Suitable Sites for the Intramuscular Injection into the Deltoid Muscle or the Gluteus Medius Muscle. Tokai University, School of Health Sciences, 9, 29-33. (In Japanese)

[10] Hara, Y., Kurokawa, K., Urai, T., Ookuwa, M. and Nakatani, T. (2010) Todatermine the Course of the Axillary Nerve, It Is Useful to Identify the Course of the Posterior Humeral Circumflex Artery That Runs along the Nerve Using a Handheld Ultrasound Blood Flowmeter and Ultrasound Diagnostic Equipment. Structure and function, 8, 59-65. (In Japanese)

[11] Komatsu, E., Mukai, K., Nakajima, Y., Ozaki, N. and Nakatani, T. (2014) Examination of the Utility of a New Tool for Intramuscular Injection Points into the Deltoid Muscle and the Safety of the Points Decided by a Method Using It. Structure and Function, 13, 17-24. (In Japanese)

[12] Sawamoto, Y., Sawamoto, M. and Takasawa, F. (2004) Text Book for Clinical Nursing Practice, Igakugeijutsusha. Igakugeijutsusha Co. Ltd., Tokyo, 129-131. (In Japanese)

[13] Institute for Health Care Information Sciences (2013) Nursing Technique Becomes Clear: Vol.2 Clinical Nursing Technique, Medic Media. (In Japanese)

[14] Potter, P.A., Perry, A.G., Stockert, P. and Hall, A. (2013) Fundamentals of Nursing. ELSEVIER, Canada, 605-608.

[15] Nakatani, T., Inagaki, M., Sugama, J., Sanada, H., Nagakawa, T., Takeda, Y., Tawara, T., Hiramatsu, T., Kawamura, K. and Ohkuwa, M. (1999) Intramuscular Injection into the Deltoid Muscle. Where Is the Suitable Site for the Injection? Memoirs of School of Health Sciences Faculty of Medicine Kanazawa University, 23, 83-86. (In Japanese)

[16] Tanioka, T., Yasuhara, Y. and Sakamaki, S. (2014) Safe Injection Method of Long Acting Injection in Psychiatry, Safe Injection Site and Injection Needle Penetration Depth Based on Evidence by Ultrasonic Diagnosis. Psychiatric Nursing, 41, 35-45. (In Japanese)

[17] Kikuchi, K. and Takahashi, Y. (2002) Study of Needle Penetration Depth in Intramuscular Injection. The 22th Academic Conference of Japan Academy of Nursing Science, Tokyo, 6-7 December 2002, 469.

[18] Takahashi, Y., Kikuchi, K., Miura, N. and Ishida, Y. (2014) Appropriate Needle Insertion Depth for Intramuscular Injection Based on Assessment of BMI. Journal of Japan Academy of Nursing Science, 34, 36-45. (In Japanese) http://dx.doi.org/10.5630/jans.34.36

[19] Handa, S. (1981) A Study Concerning Reliable Way of Subcutaneous Injection and Muscle Injection. American Journal of Nursing Research, 14, 43-50.

[20] Sakamaki, S., Yasuhara, Y., Zhao, Y., Kai, Y., Motoki, K., Takase, K. and Tanioka, T. (2015) Long-Acting Injection(LAI) Site Estimation Formula to Determine Subcutaneous Fat Thickness. Japanese Journal of Clinical Psychopharmacology, 18, 927-937. (In Japanese)

[21] Yasuhara, Y. and Tanioka, T. (2012) Points to Be Noticed for Muscle Injection: Muscle Injection, Is It True That the Injection Needle Does Not Reach the Muscle Unexpectedly? Expert Nurse, 28, 82-85. (In Japanese) 